Supporting Information

\title{
Multi-functional polymer sponge with molecule recognition: facile mechanic induced separation
}

\author{
Jin Li, Ruiqing Wang, Zhilong Su*, Xiaodong Ma, Xuesong Jiang* \\ School of Chemistry\& Chemical Engineering, State Key Laboratory for Metal Matrix \\ Composite Materials, Shanghai Jiao Tong University 200240, China. \\ E-mail: ponygle@sjtu.edu.cn; szl1989@sjtu.edu.cn
}

Number of pages: 8

Number of figures: 6

Number of tables: 3 


\section{Experiment}

\section{Materials}

polyethylene glycol diglycidyl ether (PEG-DE, $0.5 \mathrm{kDa}$ ), Polyetherimide (PEI, $10 \mathrm{kDa})$,

Caffeic acid (CA), Triaminemethane hydrochloride (Tris- $\mathrm{HCl})$, Water-soluble dyes Rose Bengal (RB), Erythrosin B (ETB), Eosin B (EB), 4,5,6,7-tetrachlorofluorescein (TCF), fluorescein (FR), 4'5'-dibromofluorescein (DBF), Calcein (Cal), Bismarck brown (BBY), Methylene Blue (MB), Ponceau S (PS) and Evans blue (EVB) used in this study were supplied by Sinopharm Chemical. All the adsorption and separation of dyes in this study were performed in phosphate buffered solution $(\mathrm{PH}=7.2)$.

\section{Instruments}

Fourier transform infrared spectroscopy (FT-IR) spectra of the products were carried out on a Paragon 1000 Fourier transformation infrared absorption spectrometer (Perkin Elmer, Inc., USA) equipped with temperature regulating device.

Scanning electron microscope (SEM) was performed on a NOVA NanoSEM 230 (FEI Company) field emission scanning electron microscope operated at an acceleration voltage of $5 \mathrm{kV}$, all of the sponges were coated with gold in vacuum before observation.

UV-vis Spectra. The UV-vis spectra were conducted with a UV-Win550 spectrophotometer (UV Win 5, TU-1901, China).

Compressive stress-strain measurements of three sponges were conducted at room temperature using an Instron 4465 instrument at a cross-head speed of $10 \mathrm{~mm} \mathrm{~min}^{-1}$. The speed of unloading was kept at $5 \mathrm{~mm} \mathrm{~min}^{-1}$, and at least three samples were evaluated for each test. The sample was prepared with a diameter of $1.8 \mathrm{~cm}$ in and a height of $2.0 \mathrm{~cm}$ in the compressive test. 


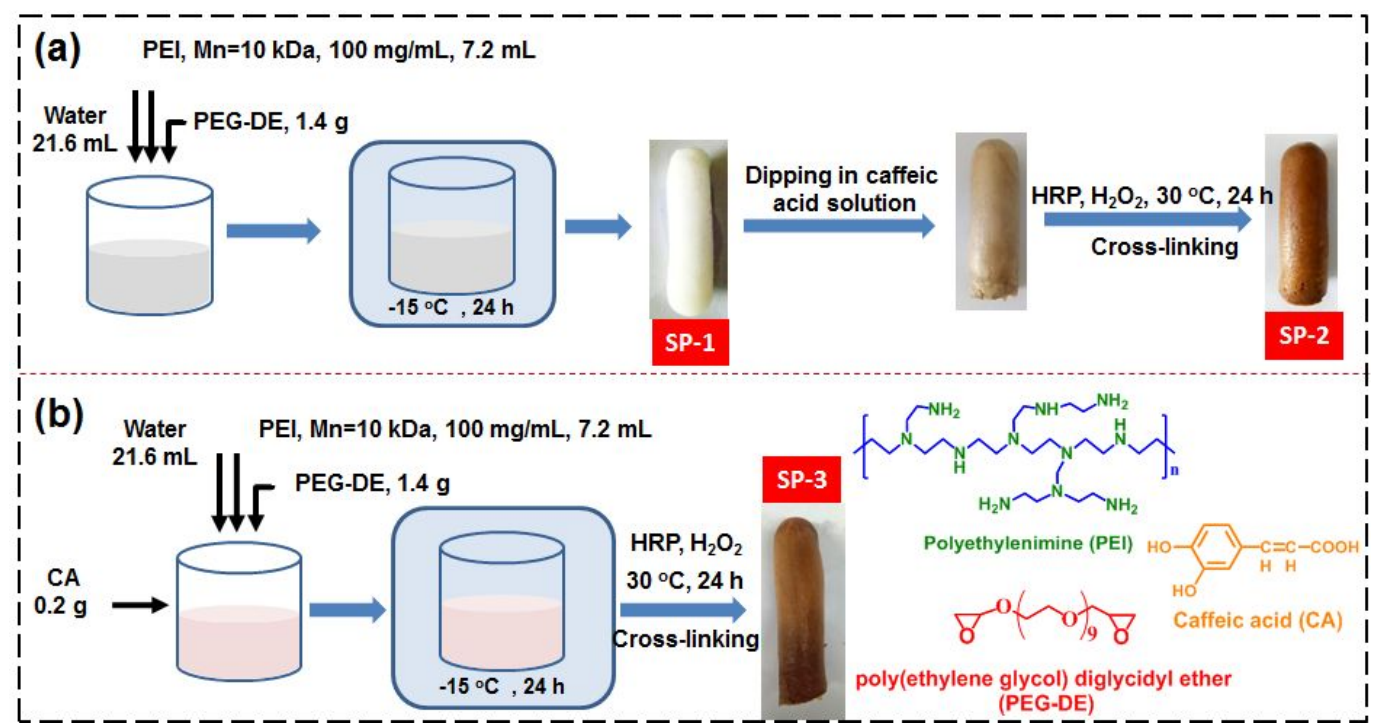

Scheme S1. Strategy for the synthesis of three sponges, SP-1 and SP-2 (a), and SP-3 (b).

(a)

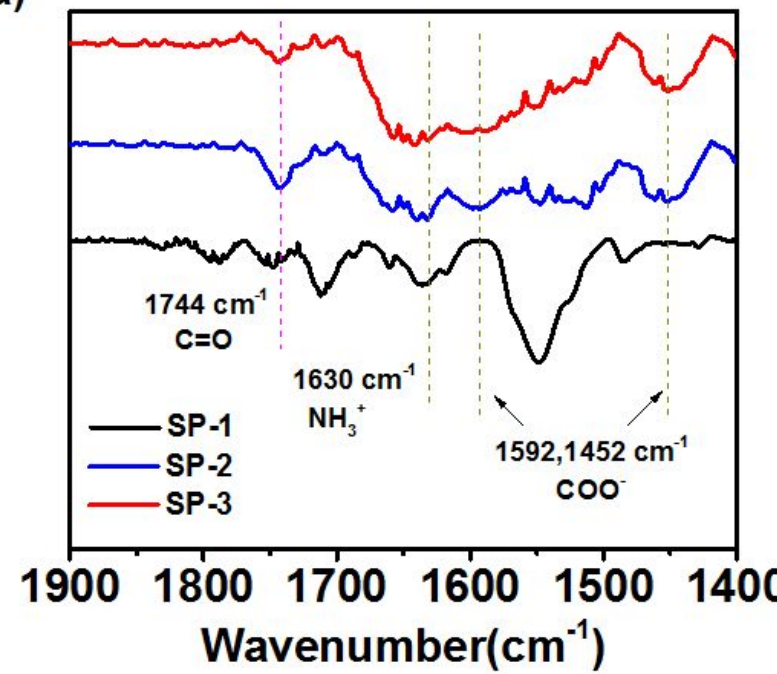

(b)

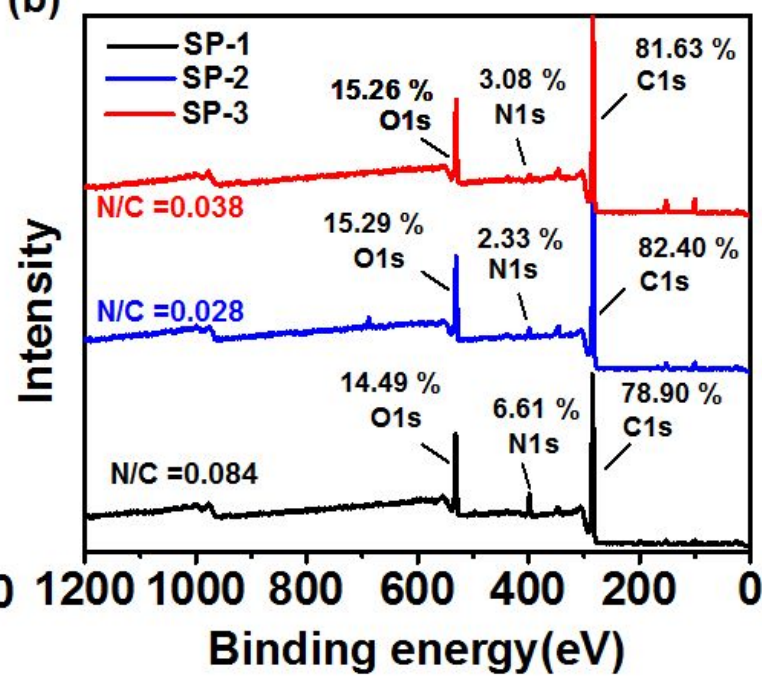

Figure S1. The reflectance FT-IR spectra (a) and XPS curves (b) of three sponges. 


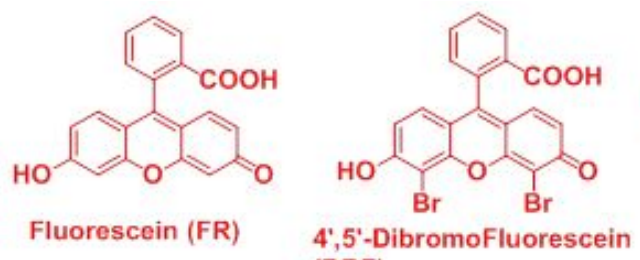
$4^{\prime}, 5^{\prime}-\mathrm{D}$
(DBF)
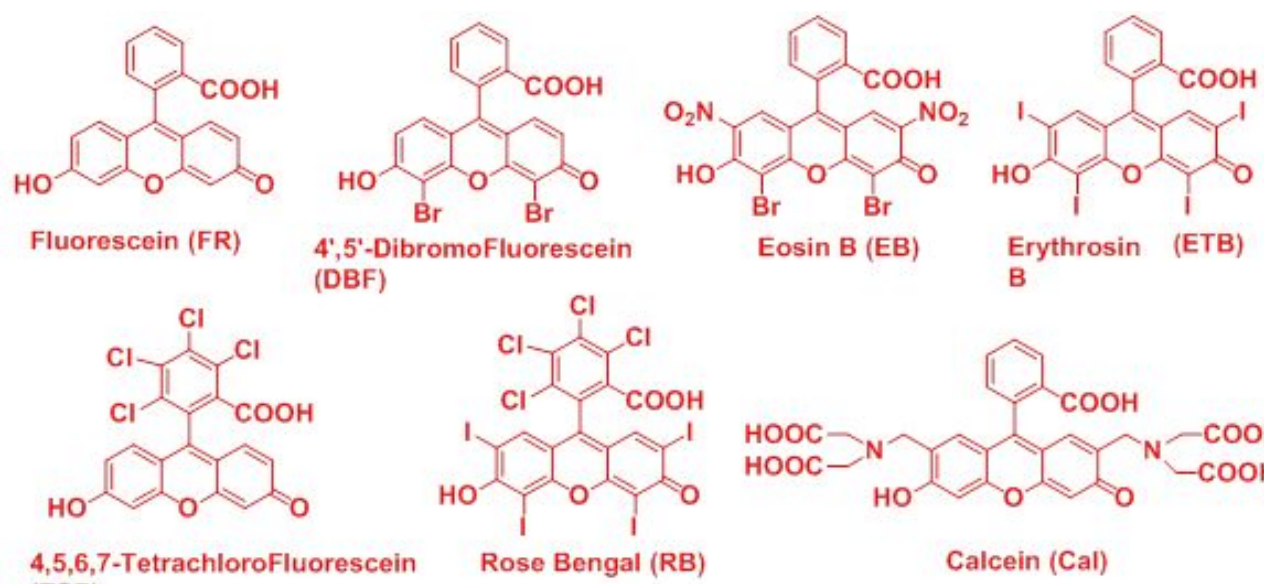

4,5,6,7-TetrachloroFluorescein (TCF)
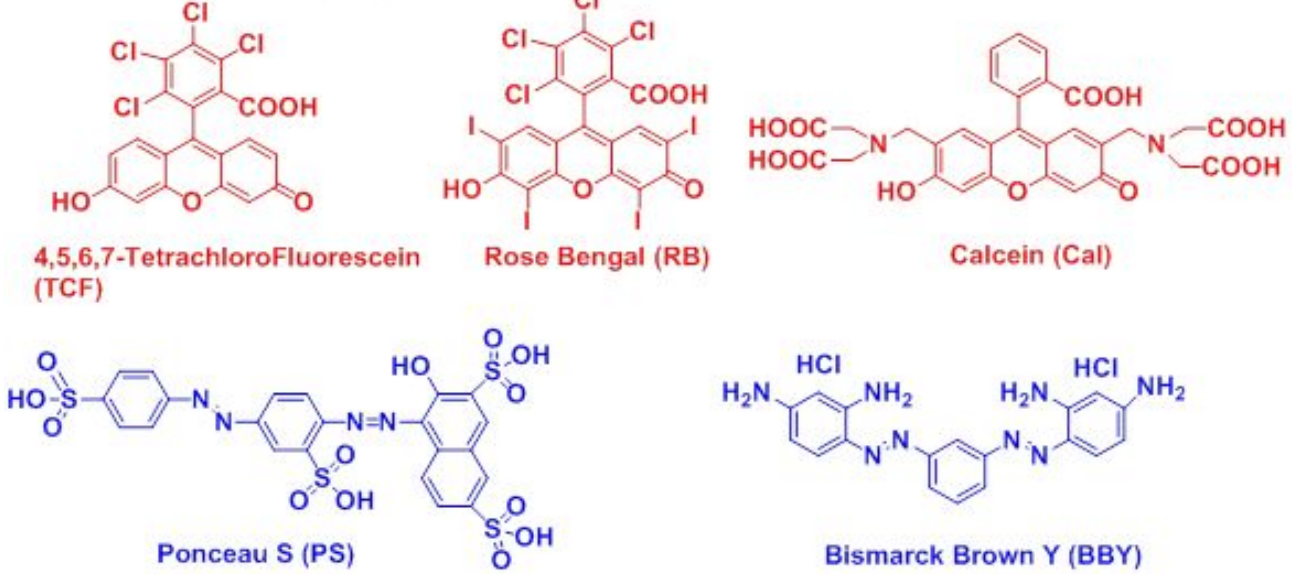

Bismarck Brown Y (BBY)
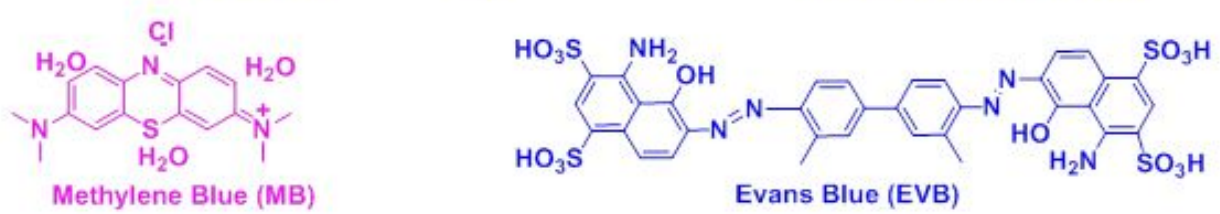

Scheme S2. Structure and abbreviation of seven fluorescein (red marked), AZO (blue marked), and phenothiazine dyes (purple marked).

Table S1. Previous reported maximum adsorption capacities of various adsorbents for methylene blue (MB).

\begin{tabular}{cccc}
\hline Adsorbent & $\begin{array}{c}\text { adsorption capacity } \\
\text { for MB }(\mathrm{mg} / \mathrm{g})\end{array}$ & $\begin{array}{c}\text { recognition and } \\
\text { separation (Yes / No) }\end{array}$ & Reference \\
\hline Nanoporous polymer & 57.7 & No & {$[1]$} \\
Polyaniline hydrogel & 37.2 & No & {$[2]$} \\
$\begin{array}{c}\text { Humic acid based } \\
\text { biopolymeric membrane } \\
\text { Sponge-based porous } \\
\text { carbons }\end{array}$ & 15.4 & Yes & {$[3]$} \\
$\begin{array}{c}\text { Active lignin-chitosan } \\
\text { blends }\end{array}$ & 57.0 & No & {$[4]$} \\
Polymer sponge (SP-2) & 36.3 & No & {$[5]$} \\
\hline
\end{tabular}

\section{The selective adsorption and separation of dyes}

\section{Adsorption kinetics}

Pseudo-second-order kinetics can be used to analyze adsorption kinetics and represented as Equation S1, which is used to analyze the adsorption mechanism of dyes.

$$
\frac{d Q_{t}}{d t}=k\left(Q_{e q}-Q_{t}\right)^{2}
$$


In this equation, $k$ is the rate constant $\left(\mathrm{g} \cdot \mu \mathrm{mol}^{-1} \cdot \mathrm{min}^{-1}\right), Q_{e q}(\mu \mathrm{mol} / \mathrm{g})$ is the adsorption at equilibrium and $t$ is the time (min). The equation becomes Equation S2 after integration, reformulation and linearization.

$$
\frac{t}{Q_{t}}=\frac{1}{k \cdot Q_{e q}^{2}}+\frac{t}{Q_{e q}}
$$

When $\frac{t}{Q_{t}}$ is plotted against $t$, the line should be straight and the slope will equal to $\frac{1}{Q_{e q}}$, and the intercept will equal to $\frac{1}{k \cdot Q_{e q}^{2}}$. Thus, $\mathrm{k}=\frac{\text { slope }^{2}}{\text { intercept }}$ and $Q_{e q}=\frac{1}{\text { slope }}$.

The plots of $\frac{t}{Q_{t}}$ versus $t$ in Figure S2 showed that pseudo-second-order equations fitted well to the whole range of the contact time with the very high correlation coefficient $\left(R^{2}\right)$. The pseudo-second-order adsorption rate constant $k$, the calculated and experimental adsorption capacity $Q_{\text {eq,cal }}$ and $Q_{\text {eq,exp }}$, and the correlation coefficient $R^{2}$ were summarized in Table S2.
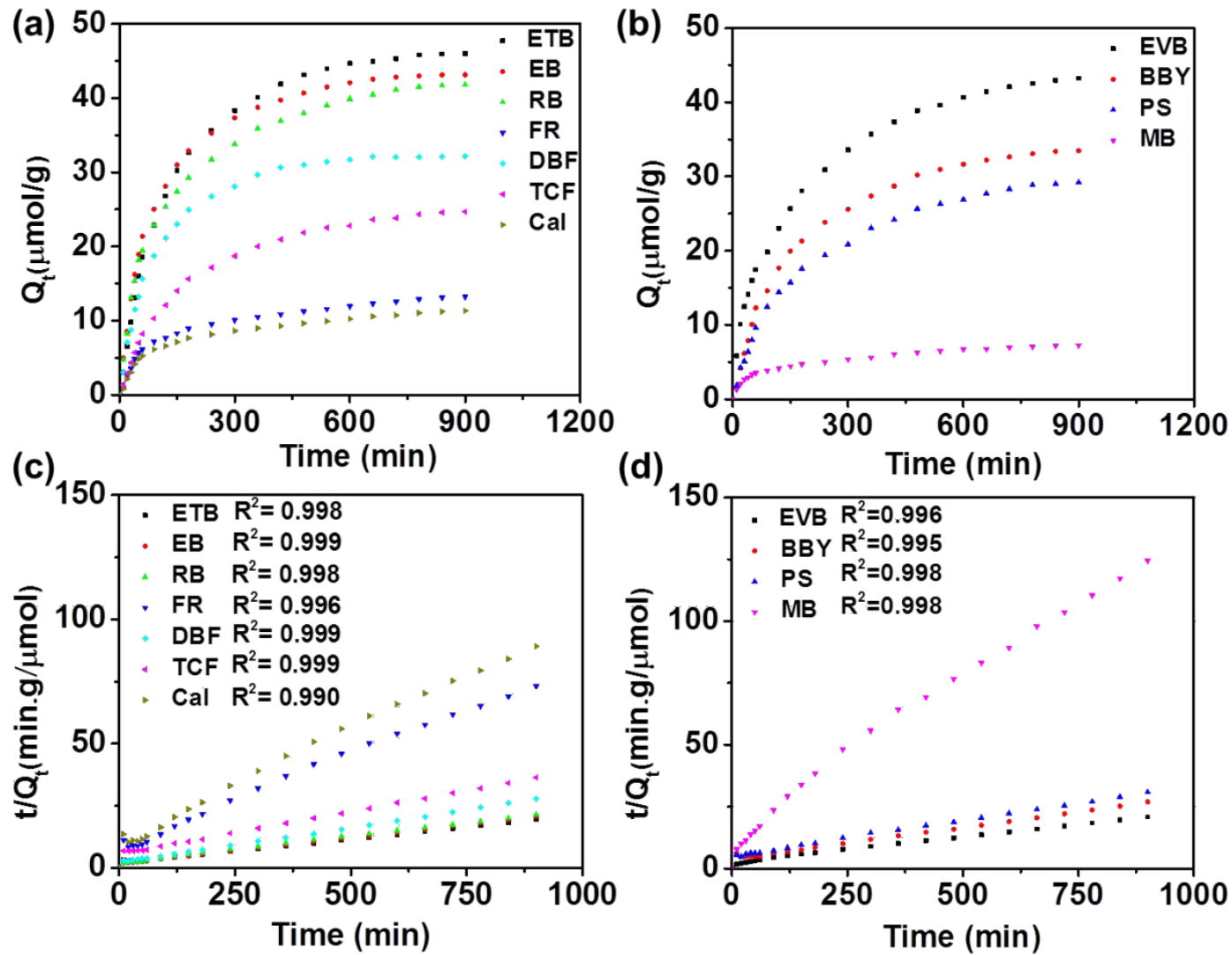

Figure S2. Adsorption capacity $Q_{t}$ versus time for the adsorption of seven fluorescein, azo, and phenothiazine dyes (a-b), Pseudo-second-order adsorption kinetics of fluorescein dyes (a) and azo and phenothiazine dyes (b) of SP-3 at $25^{\circ} \mathrm{C}$. 
Table S2. Kinetics parameters describing the adsorption of fluorescein, azo and phenothiazine dyes onto SP-3.

\begin{tabular}{|c|c|c|c|c|}
\hline \multirow[b]{2}{*}{ Dyes } & \multicolumn{4}{|l|}{ SP-3 } \\
\hline & $\underset{(\mu \mathrm{mol} / \mathrm{g})}{Q_{\text {eq,exp }}}$ & $\frac{k}{\left(\mathrm{~g} \cdot \mu \mathrm{mol}^{-1} \cdot \mathrm{min}^{-1}\right)}$ & $\underset{(\mu \mathrm{mol} / \mathrm{g})}{Q_{e q, c a l}}$ & $R^{2}$ \\
\hline ETB & 46.01 & $1.53 \mathrm{E}-04$ & 53.22 & 0.998 \\
\hline EB & 43.15 & 2.64E-04 & 47.39 & 0.999 \\
\hline $\mathrm{RB}$ & 41.80 & 2.38E-04 & 45.91 & 0.998 \\
\hline FR & 12.30 & $8.15 \mathrm{E}-04$ & 13.10 & 0.996 \\
\hline DBF & 32.13 & $3.40 \mathrm{E}-04$ & 35.70 & 0.999 \\
\hline TCF & 24.69 & $1.98 \mathrm{E}-04$ & 29.56 & 0.999 \\
\hline Cal & 10.09 & 9.93E-04 & 10.75 & 0.990 \\
\hline EVB & 43.23 & $1.92 \mathrm{E}-04$ & 47.94 & 0.996 \\
\hline BBY & 33.47 & $1.51 \mathrm{E}-04$ & 40.13 & 0.995 \\
\hline PS & 29.21 & $1.65 \mathrm{E}-04$ & 34.83 & 0.998 \\
\hline MB & 7.23 & $1.66 \mathrm{E}-03$ & 7.59 & 0.988 \\
\hline
\end{tabular}

The adsorption isotherm

Langmuir adsorption isotherm ${ }^{[5]}$

$$
\frac{C_{e q}}{Q_{e q}}=\frac{C_{e q}}{Q_{\max }}+\frac{1}{K_{L} Q_{\max }}
$$

$C_{e q}(\mu \mathrm{M} / \mathrm{L})$ is the equilibrium concentration of the dyes in the solution, $Q_{\max }(\mu \mathrm{M} / \mathrm{g})$ is the maximum capacity of the hPEA/CS-SNs, $Q_{e q}(\mu \mathrm{M} / \mathrm{g})$ is the amount of dyes adsorbed at the equilibrium, and $K_{L}(\mathrm{~L} / \mu \mathrm{M})$ is the Langmuir adsorption constant.

Freundlich adsorption isotherm ${ }^{[6]}$

$$
\ln Q_{e q}=\ln K_{F}+b_{F} \ln C_{e q}
$$

$C_{e q}(\mu \mathrm{M} / \mathrm{L})$ is the equilibrium concentration of the dyes in the solution, $K_{F}$ is the Freundlich constant, $Q_{e q}(\mu \mathrm{M} / \mathrm{g})$ is the amount of dyes adsorbed at the equilibrium, and $b_{F}$ is a constant for depicting the adsorption intensity.

Figure S3a showed the linear Langmuir isotherms for ETB, EB and Cal onto SP-3 respectively. The corresponding correlation coefficients for adsorption of ETB, EB and Cal were $0.998,0.984$, and 0.990 , respectively. The high correlation coefficients indicated that the Langmuir model was suitable to describe the adsorption equilibrium of ETB, EB and Cal by the SP-3. As showed in the linear Freundlich isotherms for ETB, EB and Cal onto SP-3 
(Figure S3b), the corresponding correlation coefficients for adsorption of ETB, EB and Cal were $0.931,0.941$, and 0.977 , respectively. The high correlation coefficient confirmed that the adsorption of ETB, EB and Cal obeyed the Langmuir isotherms model. The adsorption isotherm parameters were summarized in Table S3.
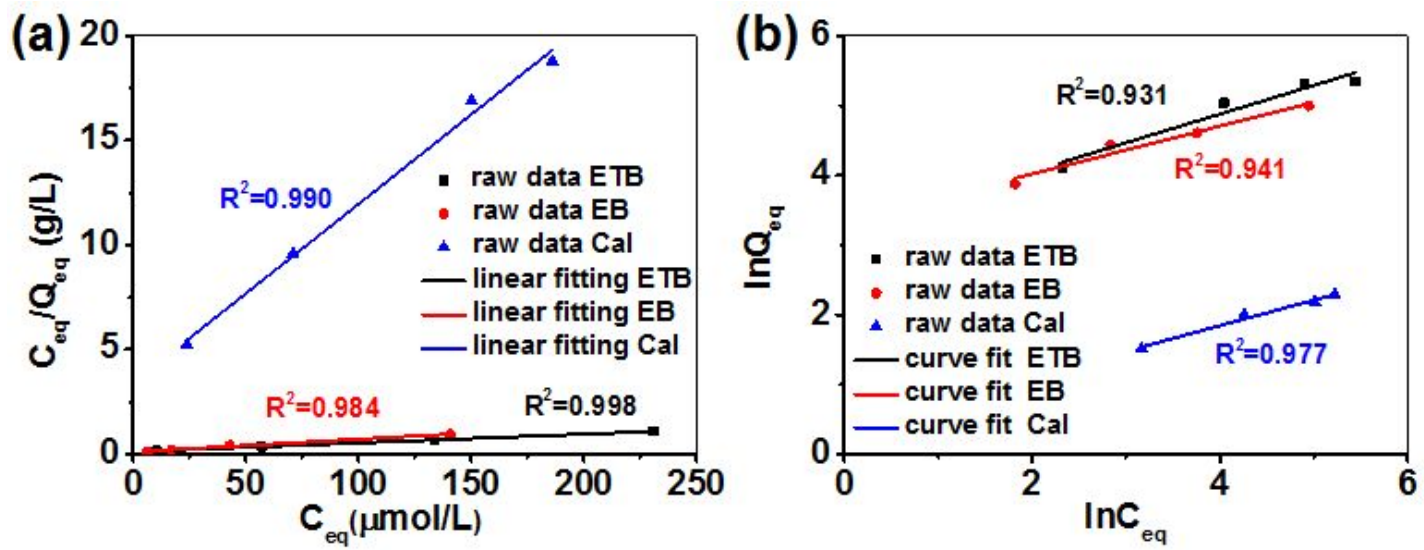

Figure S3. (a) Linearized Langmuir isotherms of ETB, EB and Cal and (b) Linearized Freundlich isotherms of ETB, EB and Cal onto SP-3 at $25^{\circ} \mathrm{C}, \mathrm{pH}=7.2$.

Table S3. Langmuir adsorption isotherm constants of ETB, EB and Cal, and Freundlich isotherm constants of ETB, EB and Cal onto SP-3.

\begin{tabular}{|c|c|c|c|c|c|c|}
\hline \multirow[b]{2}{*}{ Dyes } & \multicolumn{3}{|c|}{ Langmuir model } & \multicolumn{3}{|c|}{ Freundlich model } \\
\hline & $\underset{(\mu \mathrm{mol} / \mathrm{g})}{Q_{\max }}$ & $\begin{array}{c}K_{L} \\
(\mathbf{L} / \mu \mathrm{mol})\end{array}$ & $R^{2}$ & $b_{F}$ & $\boldsymbol{K}_{\boldsymbol{F}}$ & $\mathbf{R}^{2}$ \\
\hline ETB & 238.66 & $3.44 \mathrm{E}-02$ & 0.998 & 25.42 & 0.41 & 0.931 \\
\hline EB & 166.39 & $5.20 \mathrm{E}-02$ & 0.984 & 28.04 & 0.34 & 0.941 \\
\hline Cal & 11.69 & $2.51 \mathrm{E}-02$ & 0.990 & 1.45 & 0.36 & 0.977 \\
\hline
\end{tabular}
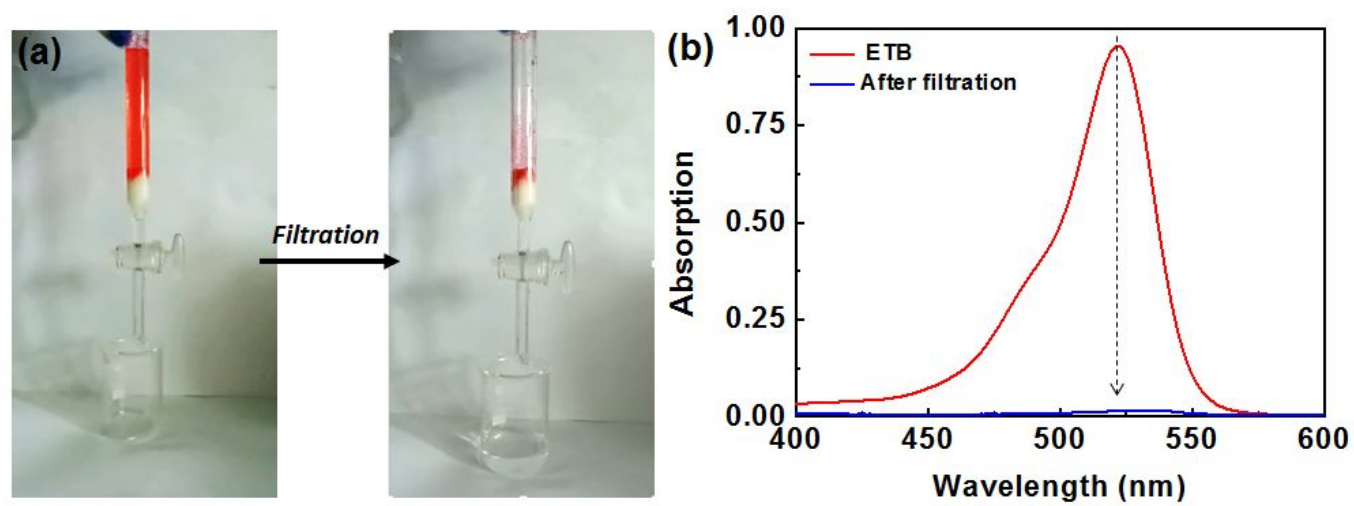

Figure S4. One-pot separation of ETB in aqueous solution by SP-1, photograph of ETB before and after separation via filtration by using SP-1 at $25^{\circ} \mathrm{C}$. (b) UV-vis spectra to trace filtration separation of ETB. 


\section{References}

[1] Su, H.; Li, W.; Han, Y.; Liu, N., Scientific reports 2018, 8 (1), 6506.

[2] Yan, B.; Chen, Z.; Cai, L.; Chen, Z.; Fu, J.; Xu, Q., Applied Surface Science 2015, 356, 39.

[3] Shenvi, S. S.; Isloor, A. M.; Ismail, A. F.; Shilton, S. J.; Al Ahmed, A., Industrial \& Engineering Chemistry Research 2015, 54 (18), 4965.

[4] Li, Z.; Wang, G.; Zhai, K.; He, C.; Li, Q.; Guo, P., Colloids and Surfaces A: Physicochemical and Engineering Aspects 2018, 538, 28.

[5] Albadarin, A. B.; Collins, M. N.; Naushad, M.; Shirazian, S.; Walker, G.; Mangwandi, C., Chemical Engineering Journal 2017, 307, 264.

[6] I. Langmuir, Journal of the American chemical society 1916, 38, 2221.

[7] H. Freundlich, Zeitschrift für physikalische Chemie 1907, 57, 385. 